\title{
Relationship Between Glycated Haemoglobin and Carotid Atherosclerotic Disease Among Patients with Acute Ischaemic Stroke
}

"Saima Nazish, Azra Zafar, Rizwana Shahid, Aishah Albakr, Fahd A. Alkhamis, Danah Aljaafari, Majed Alabdali, Abdullah Alsulaiman, Faisal A. Al-Mulla

$$
\begin{aligned}
& \text { العلاقة بين مستوى السكر التراكمي في الدم ومرض تصلب الشريان السباتي بين }
\end{aligned}
$$

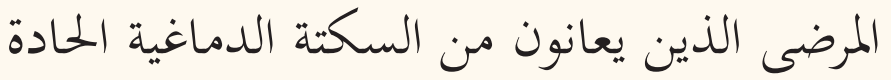

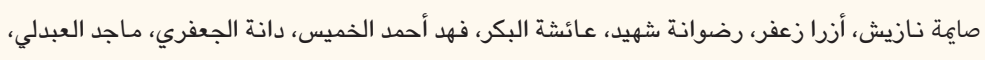

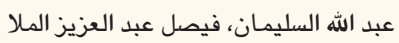

ABSTRACT: Objectives: This study aimed to determine the relationship between glycaemic control and carotid atherosclerotic disease among patients with acute ischaemic stroke (AIS). Methods: This retrospective crosssectional study took place in the Neurology Department of King Fahad Hospital of University, Khobar, Saudi Arabia, from April to October 2017. Data were collected from the medical records of 244 patients with a diagnosis of AIS confirmed by computed tomography. Doppler ultrasounds of the carotid artery were performed to determine the presence of increased carotid intima media thickness (CIMT) and plaques. Results: Significantly higher mean glycated haemoglobin (HbA1c) levels were noted in cases with high CIMT values $(P=0.002)$, but not in cases with carotid plaques $(P=0.360)$. In addition, there was a significant association between diabetes mellitus (DM) and high CIMT $(P=0.045)$, but not with carotid plaques $(P=0.075)$. Finally, while dyslipidaemia and age were independently correlated with high CIMT values $(P=0.034$ and $<0.001$, respectively) and carotid plaques $(P<0.001$ each), no independent relationships were noted in terms of gender and other risk factors like DM, hypertension and smoking $(P>0.050$ each). Conclusion: High HbA1c levels were associated with high CIMT values, but not with carotid plaques. Therefore, HbA1c levels may be useful as an indirect marker of the initial stages of carotid artery atherosclerosis.

Keywords: Glycated Hemoglobin A1c; Diabetes Mellitus; Carotid Intima-Media Thickness; Atherosclerotic Plaque; Stroke.

الملخص: الهذف: هدفت هذه الدراسة الي تحديد العلاقة بين السيطرة على نسبة السكر في الدم ومرض تصدئ تصلب الثرايين السباتي بين

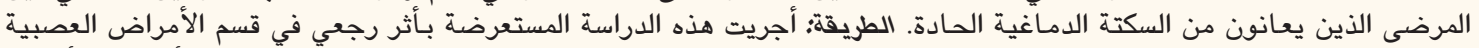

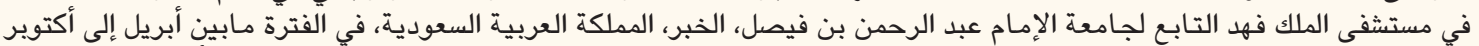

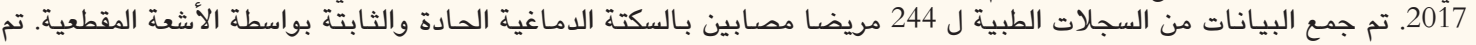

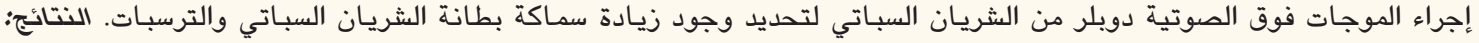

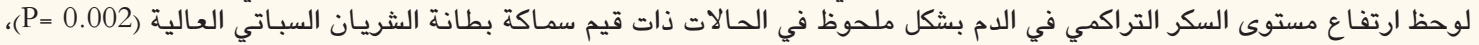

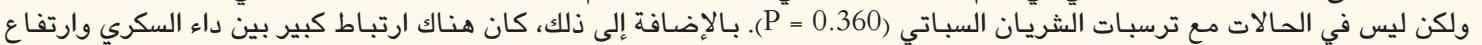

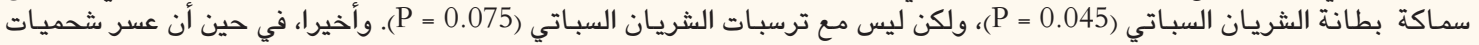

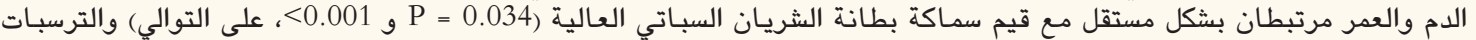

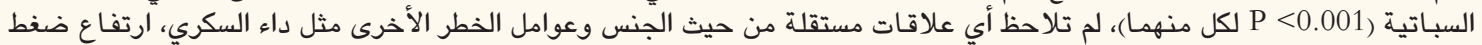

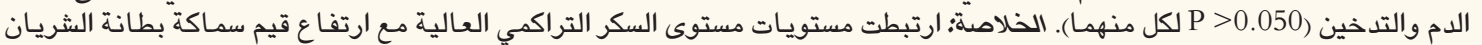

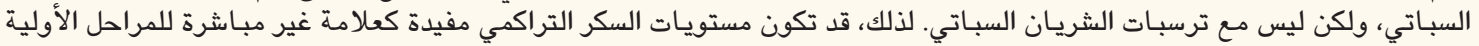
من تصلب الثرايين السباتية.

الكلمات المفتاحية؛ مستوى السكر التراكمي؛ داءالسكرى؛ سماكة بطانة الثريان السباتي؛ ترسبات الشريان؛ السكتة الدماغية.

\section{Advances in KNOWledge}

The association between glycated haemoglobin (HbA1c) and carotid intima-media thickness (CIMT) has been studied in different populations. This study demonstrated a relationship between HbA1c and CIMT in patients with ischaemic stroke.

\section{Application to Patient Care}

The findings of this study may help in the early recognition of carotid artery atherosclerotic disease as well as in the formulation of strategies and guidelines for stroke prevention. However, further clinical research regarding different stroke risk factors would be beneficial. 
E XTRACRANIAL CAROTID ARTERY ATHEROSClerotic disease is an important thromboembolic cause of stroke and a key target in stroke prevention. ${ }^{1}$ In addition, growing evidence suggests that carotid atherosclerotic disease is a risk factor for neurocognitive dysfunction. ${ }^{2}$ Approximately 30\% of ischaemic strokes are caused by carotid occlusive disease. ${ }^{3}$ The sensitivity and specificity of a carotid Doppler ultrasound-which measures the reduction in carotid diameter as well as the carotid intima media thickness (CIMT) - is 90-95\%, making it highly sensitive for the detection of atherosclerotic plaques. ${ }^{4}$ According to previous research, CIMT increases in patients with diabetes mellitus (DM). ${ }^{5}$ Moreover, raised glycated haemoglobin (HbA1c) levels are related to the risk of carotid atherosclerotic plaques as well as their subsequent thickening and hardening. Such plaque changes are an independent risk factor for stroke, with the risk abruptly increasing at an $\mathrm{HbA} 1 \mathrm{c}$ level of $>7 \%$ regardless of a diagnosis of DM. ${ }^{6-8}$

In addition to predicting overall stroke risk, poor glycaemic control also influences functional outcomes following an ischaemic stroke. Recovery largely depends on the intrinsic rewiring and remapping of damaged structures, along with surviving regions. The damage induced by chronically altered glycaemic levels is not limited to the extracranial large vessels but also involves the vascular and neural pathways in the brain. ${ }^{9}$ The effect of chronic hyperglycaemia-induced metabolic dysfunction on the structure and function of the cerebrovascular system leads to impaired blood supply to the salvageable penumbra zone through the collateral vessels and increases susceptibility to reperfusion injuries. Thus, chronic exposure to abnormally high glycaemic levels may significantly impair reparative neovascularisation and reduce neural circuit functional plasticity. ${ }^{9}$

The association between HbA1c and CIMT has been studied in various populations. ${ }^{10,11}$ In addition, previous studies have analysed the frequency of carotid artery stenosis among patients with stroke as well as those with severe triple vessel coronary artery disease and DM. ${ }^{12,13}$ Choi et al. studied the association between HbA1c levels and arterial stiffness and peripheral arterial disease among Korean patients with type 2 DM. ${ }^{14}$ However, there is a lack of local data from Saudi Arabia analysing the relationship between glycaemic control and carotid atherosclerotic disease. This study therefore aimed to investigate the relationship between elevated HbA1c levels and CIMT and carotid plaques in ischaemic stroke patients in Saudi Arabia. This population is susceptible to multiple vascular risk factors as well as a rising prevalence of neurocognitive disorders and stroke, with evidence of both small vessel disease and large vessel occlusion. ${ }^{15,16}$

\section{Methods}

This retrospective cross-sectional study was carried out in the Department of Neurology, King Fahad Hospital of University, Khobar, Saudi Arabia, between April and October 2017. Retrospective data were collected from the medical records of 400 adult patients with acute ischaemic stroke (AIS) seen at an affiliated hospital between February 2010 and September 2016. As per the guidelines of the World Health Organization, AIS was defined as "rapidly developed clinical signs of focal (or global) disturbance of cerebral function, lasting more than 24 hours or leading to death, with no apparent cause other than of vascular origin".17 All AIS diagnoses were confirmed by cranial computed tomography. Patients with isolated transient ischaemic attacks, strokes of cardioembolic aetiology or due to vasculitis syndromes and those with coagulation disorders were excluded. Therefore, a final sample of 244 patients with AIS were included in the study.

High-resolution B-mode carotid Doppler ultrasonography of each patient was performed by a radiologist using a MyLab ${ }^{\text {TM }}$ Class $C^{\circledR} 7 \mathrm{MHz}$ linear transducer (Esaote Group, Genoa, Italy), as per international guidelines. ${ }^{18}$ The CIMT was calculated as the mean maximal intima media thickness of each carotid artery measured at both the bifurcation and the internal carotid arteries. A CIMT value of $>0.8 \mathrm{~mm}$ was considered high, as this cut-off value has been found to correlate with vascular risk factors. ${ }^{19,20}$ A plaque was defined as a localised protrusion of the internal part of the vessel wall into the lumen with a thickness of $>1.5 \mathrm{~mm}$ between the intimalumen and media-adventitia interfaces. ${ }^{21} \mathrm{HbA1c}$ levels were measured using high-performance liquid chromatography with a G8 HPLC Analyser ${ }^{\circledR}$ (Tosoh Bioscience Inc., San Francisco, California, USA) as per the National Glycohemoglobin Standardization Program guidelines. ${ }^{22}$

According to the American Diabetes Association criteria, DM was defined as either a fasting glucose level of $\geq 126 \mathrm{mg} / \mathrm{dL}$ or an HbA1c level of $\geq 6.5 \%{ }^{23}$ Other risk factors for stroke and carotid artery disease were also noted, such as hypertension (HTN), dyslipidaemia and smoking. HTN was defined as a systolic or diastolic blood pressure (BP) of $>140 \mathrm{mmHg}$ or $90 \mathrm{mmHg}$, respectively. Dyslipidaemia was defined as a fasting serum cholesterol level of $>200 \mathrm{mg} / \mathrm{dL}$, triglyceride level of $>150 \mathrm{mg} / \mathrm{dL}$, low-density lipoprotein level of $>120 \mathrm{mg} / \mathrm{dL}$ and a high-density lipoprotein level of $35-60 \mathrm{mg} / \mathrm{dL} .{ }^{24}$ However, a higher HDL cut-off point $(<40 \mathrm{mg} / \mathrm{dL})$ was used when assessing cardiac risk in female patients, given the observed incidence of coronary disease in women with comparatively higher HDL-C levels than men. ${ }^{25}$ 
Table 1: Demographic and clinical characteristics of acute ischaemic stroke patients according to diabetes status $(\mathrm{N}=244)$

\begin{tabular}{|c|c|c|c|}
\hline \multirow{2}{*}{ Characteristic } & \multicolumn{3}{|c|}{ n (\%) } \\
\hline & Total & $\begin{array}{l}\text { Diabetic } \\
\text { patients } \\
(\mathbf{n}=140)\end{array}$ & $\begin{array}{l}\text { Non- } \\
\text { diabetic } \\
\text { patients } \\
(n=104)\end{array}$ \\
\hline \multicolumn{4}{|l|}{ Gender } \\
\hline Male & $160(65.6)$ & $93(66.4)$ & $67(64.4)$ \\
\hline Female & $84 .(34.4)$ & $47(33.6)$ & $37(35.6)$ \\
\hline \multicolumn{4}{|l|}{ Age in years } \\
\hline$\leq 50$ & $74(30.3)$ & $41(29.3)$ & $33(31.7)$ \\
\hline $51-60$ & $26(10.7)$ & $19(13.6)$ & $7(6.7)$ \\
\hline $61-70$ & $54(22.1)$ & $32(22.9)$ & $22(21.2)$ \\
\hline$>70$ & $90(36.9)$ & $48(34.3)$ & $42(40.4)$ \\
\hline Mean \pm SD & $64.3 \pm 14.5$ & $64.4 \pm 13.5$ & $64.2 \pm 15.9$ \\
\hline Range & $26-120$ & $34-98$ & $26-120$ \\
\hline \multicolumn{4}{|l|}{ Risk factors* } \\
\hline HTN & $193(79.1)$ & $118(84.3)$ & $75(72.1)$ \\
\hline Dyslipidaemia & $185(75.8)$ & $118(84.3)$ & $67(64.4)$ \\
\hline Smoking & $49(20.1)$ & $32(22.9)$ & $17(16.3)$ \\
\hline $\begin{array}{l}\text { HTN and dyslip- } \\
\text { idaemia }\end{array}$ & $144(59)$ & $93(66.4)$ & $51(49)$ \\
\hline HTN and smoking & $35(14.3)$ & $26(18.6)$ & $9(8.7)$ \\
\hline $\begin{array}{l}\text { Dyslipidaemia } \\
\text { and smoking }\end{array}$ & $40(16.3)$ & $29(20.7)$ & $11(10.6)$ \\
\hline $\begin{array}{l}\text { HTN, dyslipi- } \\
\text { daemia and } \\
\text { smoking }\end{array}$ & $31(12.7)$ & $24(17.1)$ & $7(6.7)$ \\
\hline \multicolumn{4}{|l|}{ Type of stroke } \\
\hline LAA & $113(46.3)$ & $66(47.1)$ & $47(45.2)$ \\
\hline SVD & $131(53.7)$ & $74(52.9)$ & $57(54.8)$ \\
\hline \multicolumn{4}{|l|}{ CIMT in mm } \\
\hline$>0.8$ & $140(57.4)$ & $88(62.9)$ & $52(50)$ \\
\hline$<0.8$ & $104(42.6)$ & $52(37.1)$ & $52(50)$ \\
\hline \multicolumn{4}{|c|}{ Presence of carotid plaques } \\
\hline Yes & $117(48)$ & $74(52.9)$ & $43(41.3)$ \\
\hline No & $127(52)$ & $66(47.1)$ & $61(58.7)$ \\
\hline \multicolumn{4}{|l|}{ HbAlc level in \% } \\
\hline Mean \pm SD & $7.4 \pm 2.2$ & $8.6 \pm 2.2$ & $5.7 \pm 0.8$ \\
\hline Range & $3.8-14.0$ & $5.0-14.0$ & $3.8-10.0$ \\
\hline \multicolumn{4}{|c|}{$\begin{array}{l}S D=\text { standard deviation; } H T N=\text { hypertension; } L A A=\text { large artery } \\
\text { atherosclerosis; } S V D=\text { small vessel disease } ; C I M T=\text { carotid intima } \\
\text { media thickness; } H b A 1 c=\text { glycated haemoglobin. }\end{array}$} \\
\hline $\begin{array}{l}\text { Percentages do not ac } \\
\text { several risk factors. }\end{array}$ & $p$ to $100 \%$ a & ne patients & have had \\
\hline
\end{tabular}

Table 2: Relationship between glycated haemoglobin and carotid intima media thickness and carotid plaques in acute ischaemic stroke patients $(\mathrm{N}=244)$

\begin{tabular}{|c|c|c|c|}
\hline Variable & n (\%) & $\begin{array}{c}\text { Mean HbA1c } \\
\text { level in } \% \pm \text { SD }\end{array}$ & $P$ value \\
\hline \multicolumn{4}{|c|}{ CIMT in $\mathrm{mm}$} \\
\hline$>0.8$ & $140(57.4)$ & $7.8 \pm 2.4$ & \multirow{2}{*}{0.002} \\
\hline$<0.8$ & $104(42.6)$ & $6.9 \pm 1.8$ & \\
\hline \multicolumn{4}{|c|}{ Presence of carotid plaques } \\
\hline Yes & $117(48)$ & $7.5 \pm 2.3$ & \multirow{2}{*}{0.360} \\
\hline No & $127(52)$ & $7.3 \pm 2.2$ & \\
\hline
\end{tabular}

Table 3: Association between carotid intima media thickness and carotid plaques presence in acute ischaemic stroke patients according to diabetes status $(\mathrm{N}=244)$

\begin{tabular}{|c|c|c|c|}
\hline \multirow[t]{2}{*}{ Variable } & \multicolumn{2}{|c|}{ n (\%) } & \multirow[t]{2}{*}{$P$ value ${ }^{*}$} \\
\hline & $\begin{array}{l}\text { Diabetic patients } \\
\quad(\mathrm{n}=140)\end{array}$ & $\begin{array}{c}\text { Non-diabetic } \\
\text { patients } \\
(\mathbf{n}=104)\end{array}$ & \\
\hline \multicolumn{4}{|c|}{ CIMT in mm } \\
\hline$>0.8$ & $88(62.9)$ & $52(50)$ & \multirow{2}{*}{0.045} \\
\hline$<0.8$ & $52(37.1)$ & & \\
\hline \multicolumn{4}{|c|}{ Presence of carotid plaques } \\
\hline Yes & $74(52.9)$ & $43(41.3)$ & \multirow{2}{*}{0.075} \\
\hline No & $66(47.1)$ & $61(58.7)$ & \\
\hline
\end{tabular}

Data were analysed using the Statistical Package for the Social Sciences (SPSS), Version 20.0 (IBM Corp., Armonk, New York, USA). The results were presented as frequencies and percentages for age, gender, DM, HTN, smoking, dyslipidaemia, stroke subtype, high/normal CIMT and the presence/absence of carotid plaques and means and standard deviations for age and $\mathrm{HbA1c}$ level. An independent $t$-test was used to compare means and a Chi-squared test was used to compare categorical variables. A $P$ value of $<0.050$ was deemed statistically significant. A logistic regression analysis was performed to ascertain the effects of age, gender, HTN, dyslipidaemia, smoking and HbA1c level on the likelihood of high CIMT values and carotid plaques.

Ethical approval for this study was received from the Institutional Review Board of Imam Abdulrahman Bin Faisal University (\#IRB-2017-01026). 
Table 4: Predictors of carotid intima media thickness and carotid plaques in acute ischaemic stroke patients $(\mathrm{N}=244)$

\begin{tabular}{|c|c|c|c|c|}
\hline \multirow[t]{2}{*}{ Risk factor } & \multicolumn{2}{|c|}{ High CIMT ${ }^{*}$} & \multicolumn{2}{|c|}{ Carotid plaques } \\
\hline & Adjusted OR (95\% CI) & $P$ value & Adjusted OR (95\% CI) & $P$ value \\
\hline Age & $1.95(0.87-2.17)$ & $<0.001$ & $1.87(0.85-2.05)$ & $<0.001$ \\
\hline Gender & $0.82(0.44-1.15)$ & 0.532 & $0.72(0.36-1.45)$ & 0.367 \\
\hline DM & $0.78(0.38-1.60)$ & 0.519 & $1.41(0.63-3.15)$ & 0.401 \\
\hline HTN & $1.56(0.78-3.10)$ & 0.205 & $2.10(0.92-4.78)$ & 0.070 \\
\hline Dyslipidaemia & $2.06(1.05-4.04)$ & 0.034 & $2.88(1.30-6.37)$ & $<0.001$ \\
\hline Smoking & $1.92(0.88-4.15)$ & 0.097 & $1.79(0.77-4.15)$ & 0.170 \\
\hline HbAlc & $0.81(0.68-0.96)$ & 0.019 & $0.97(0.82-1.16)$ & 0.811 \\
\hline Hosmer-Lemeshow goodness-of-fit & 0.08 & & 0.45 & \\
\hline
\end{tabular}

$C I M T=$ carotid intima-media thickness; $O R=$ odds ratio; $C I=$ confidence interval; $D M=$ diabetes mellitus; $H T N=$ hypertension; HbAlc = glycated haemoglobin . *A CIMT value of $>0.8 \mathrm{~mm}$.

\section{Results}

Overall, 244 patients with AIS were included in the study. Of these, $65.6 \%$ were male and the mean age was 64.3 \pm 14.5 years. Most patients were $\geq 61$ years old (59\%). A total of 193 patients were hypertensive (79.1\%), 185 had dyslipidaemia (75.8\%), 140 were diabetic (57.4\%) and 49 were smokers (20.1\%). Among the diabetics, the prevalence of HTN, dyslipidaemia and smoking was $84.3 \%$, $84.3 \%$ and $22.9 \%$, respectively. There were 93 patients (66.4\%) with both HTN and dyslipidaemia, 26 smokers with HTN (18.6\%) and 29 smokers with dyslipidaemia (20.7\%). In 24 cases, all four risk factors were present (17.1\%). More than half of the patients (53.7\%) had small vessel disease, while $46.3 \%$ had large artery atherosclerosis. High CIMT values were observed in 140 cases (57.4\%), while carotid plaques were present in 117 (48\%). Mean HbA1c levels were higher among diabetic patients compared to non-diabetic patients ( $8.6 \pm 2.2 \%$ versus $5.7 \pm 0.8 \%$ ) $7.4 \pm 2.2 \%$ [Table 1]. This difference was statistically significant $(P<0.001)$.

In addition, mean $\mathrm{HbA1c}$ levels were significantly higher in patients with high CIMT values compared to those with normal CIMT values $(7.8 \pm 2.4 \%$ versus $6.9 \pm 1.8 \% ; P=0.002)$. However, there was no significant difference in the mean $\mathrm{HbA1c}$ levels of patients with carotid plaques compared to those without $(7.5 \pm 2.3 \%$ versus $7.3 \pm 2.2 \% ; P=0.360$ ) [Table 2]. Finally, a significant association was observed between the frequency of high CIMT values and the presence of DM (62.9\% versus 50\%; $P=0.045)$. However, no significant association was found between the frequency of carotid plaques and the presence of DM (52.9\% versus $41.3 \% ; P=0.075)$ [Table 3].

According to the logistic regression analysis, dyslipidaemia (odds ratio [OR]: 2.06, confidence interval [CI]: 1.05-4.04; $P=0.034$ ), HbA1c levels (OR: 0.81, CI: $0.68-0.96 ; P=0.019)$ and age (OR: $1.95, \mathrm{CI}: 0.87-2.17$;
$P<0.001)$ were independent predictors of high CIMT values. Similarly, dyslipidaemia (OR: 2.88, CI: 1.30-6.37; $P<0.001)$ and age (OR: $1.87, \mathrm{CI}: 0.85-2.05 ; P<0.001$ ) were independently correlated with carotid plaques. However, gender (OR: 0.82, CI: 0.44-1.15; $P=0.532$ ), DM (OR: 0.78, CI: 0.38-1.60; $P=0.519$ ), HTN (OR: 1.56, CI: $0.78-3.10 ; P=0.205)$ and smoking (OR: 1.92, CI: $0.88-4.15 ; P=0.097)$ were not independently correlated with CIMT. Similarly, gender (OR: 0.72, CI: 0.36-1.45; $P=0.367$ ), HbA1c levels (OR: 0.97, CI: 0.82-1.16; $P=0.811$ ), DM (OR: 1.41, CI: 0.63-3.15; $P=0.401)$, HTN (OR: 2.10, CI: 0.92-4.78; $P=0.070)$ and smoking (OR: 1.79, CI: 0.77-4.15; $P=0.170$ ) were not independently correlated with carotid plaques [Table 4].

\section{Discussion}

Assessing HbA1c levels is a useful method of determining glucose control. Such testing is now recommended not only for diagnosing DM and pre-DM, but also for predicting cardiovascular risk. ${ }^{26}$ It has been suggested that glucose variability strongly correlates with $\mathrm{HbA1c}$ levels among elderly male patients with type 2 DM. ${ }^{27}$ Fluctuations in glucose levels can harm the arterial wall due to oxidative stress and endothelial dysfunction. ${ }^{28}$ Furthermore, glycaemic status is strongly associated with all grades of carotid artery disease. ${ }^{29}$ The risk of major adverse cardiovascular events is significantly higher among type 2 DM patients who have had the disease for a long time and who have advanced carotid artery stenosis. $^{30}$

B-mode ultrasonography is a noninvasive method of measuring intimal thickness, plaque formation and stenosis in the peripheral arteries. An increase in CIMT is an early manifestation of carotid artery atherosclerosis; this is subsequently followed by plaque formation 
and then carotid stenosis due to the narrowing of the lumen. ${ }^{29,31}$ Several studies have shown that Doppler ultrasonography of the carotid artery can help to predict subsequent major adverse cardiovascular events. ${ }^{31,32}$

The demographic characteristics of the sample included in the present study were similar to those of previous research concerning ischaemic stroke patients. In accordance with other studies conducted in the Gulf region, the majority of patients were male. ${ }^{16,33}$ Critically, $30.3 \%$ of cases were under 50 years of age, indicating a relatively young age of stroke onset. Dyslipidaemia was the second most frequent risk factor; however, this finding requires further verification with populationbased prospective studies. The prevalence of DM in the current study was slightly lower than reported in a previous study of AIS patients in Khobar (57.4\% versus 62.7\%). ${ }^{16}$ The mean HbA1c level was comparable to that reported by Singh et al. among stroke patients in India $(7.4 \pm 2.2 \%$ versus $7.51 \pm 1.75 \%){ }^{20}$

In the current study, high CIMT values and carotid artery plaques were present in $57.4 \%$ and $48 \%$ of cases, respectively. The relation between $\mathrm{HbA1c}$ levels and CIMT and carotid plaques has been addressed in several studies. Saha et al. found that the prevalence of high CIMT in stroke patients was $\approx 71 \%{ }^{34}$ Singh et al. noted high $\mathrm{HbA1c}$ concentrations in ischaemic stroke patients with high CIMT values and carotid plaque while Lee et al. noted an increase in CIMT and plaque formation among ischaemic stroke patients with DM. ${ }^{20,35}$ The present study similarly found that HbA1c level-as a reflection of poor glycaemic control-was significantly higher among AIS patients with high CIMT values. In contrast, HbA1c level was not significantly associated with carotid plaques. This might be due to the high frequency of HTN and dyslipidaemia in the sample which may have confounded the results.

According to a logistic regression analysis, dyslipidaemia was an independent risk factor for both high CIMT and plaque formation in the current study. Carotid plaque formation is thought to be multifactorial. Cardoso et al. reported that type 2 DM, advanced age, being male, smoking and ambulatory BP (particularly night-time pulse pressure) were the main independent predictors of atherosclerosis. ${ }^{36}$ In another study, Kowall et al. concluded that CIMT is highly dependent on traditional cardiovascular risk factors; however, the association between blood glucose levels and CIMT disappears after risk factor adjustment. ${ }^{37}$

The present study was subject to certain limitations. First, as the study was retrospective, the exact duration of DM and increased HbA1c levels could not be established. Second, some of the patients had multiple risk factors which can confound associations. Performing a risk factor adjustment would therefore have strengthened the results. Third, data regarding BP variability-which affects stroke outcomes in carotid artery occlusion and is an important predictor of carotid artery disease-were lacking. ${ }^{38,39}$ Finally, although Doppler ultrasonography has high sensitivity, there is nevertheless a risk of operatordependent variability.

\section{Conclusion}

Among the studied sample of AIS patients, high $\mathrm{HbA1c}$ levels were significantly associated with high CIMT values, but not with carotid plaques. Accordingly, HbA1c may be beneficial as an indirect marker of the initial stages of carotid artery atherosclerosis. Further clinical studies adjusting for risk factors are recommended to determine the true relationship between glycaemic control and carotid artery disease.

\section{ACKNOWLEDGEMENTS}

This study made use of the computational resources and technical services of the Scientific \& High Performance Computing Center at Imam Abdulrahman Bin Faisal University.

\section{CONFLICT OF INTEREST}

The authors declare no conflicts of interest.

\section{FUNDING}

No funding was received for this study.

\section{References}

1. Eliasziw M, Kennedy J, Hill MD, Buchan AM, Barnett HJ; North American Symptomatic Carotid Endarterectomy Trial Group. Early risk of stroke after a transient ischemic attack in patients with internal carotid artery disease. CMAJ 2004; 170:1105-9. doi: $10.1503 /$ cmaj.1030460

2. Lattanzi S, Carbonari L, Pagliariccio G, Bartolini M, Cagnetti C, Viticchi G, et al. Neurocognitive functioning and cerebrovascular reactivity after carotid endarterectomy. Neurology 2018; 90:e307-15. doi: 10.1212/WNL.0000000000004862.

3. Strickman NE, Loyalka P. Carotid artery stenosis: An endovascular specialist's perspective. Tex Heart Inst J 2005; 32:318-22.

4. Jahromi AS, Cinà CS, Liu Y, Clase CM. Sensitivity and specificity of color duplex ultrasound measurement in the estimation of internal carotid artery stenosis: A systematic review and meta-analysis. J Vasc Surg 2005; 41:962-72. doi: 10.1016/j.jvs.20 05.02.044.

5. Cheng KS, Mikhailidis DP, Hamilton G, Seifalian AM. A review of the carotid and femoral intima-media thickness as an indicator of the presence of peripheral vascular disease and cardiovascular risk factors. Cardiovasc Res 2002; 54:528-38. doi: 10.10 16/S0008-6363(01)00551-X.

6. Jørgensen L, Jenssen T, Joakimsen $\mathrm{O}$, Heuch I, Ingebretsen OC, Jacobson BK. Glycated hemoglobin level is strongly related to the prevalence of carotid artery plaques with high echogenicity in nondiabetic individuals: The Tromsø study. Circulation 2004; 110:466-70. doi: 10.1161/01.CIR.0000136809.55141.3B. 
7. Syed IA, Khan WA. Glycated haemoglobin: A marker and predictor of cardiovascular disease. J Pak Med Assoc 2011; 61:690-5.

8. Myint PK, Sinha S, Wareham NJ, Bingham SA, Luben RN, Welch AA, et al. Glycated hemoglobin and risk of stroke in people without known diabetes in the European Prospective Investigation into Cancer (EPIC)-Norfolk prospective population study: A threshold relationship? Stroke 2007; 38:271-5. doi: 10.11 61/01.STR.0000254549.75763.5f.

9. Lattanzi S, Bartolini M, Provinciali L, Silvestrini M. Glycosylated hemoglobin and functional outcome after acute ischemic stroke. J Stroke Cerebrovasc Dis 2016; 25:1786-91. doi: 10.1016/j. jstrokecerebrovasdis.2016.03.018.

10. Hung CS, Lee PC, Li HY, Ma WY, Lin MS, Wei JN, et al. Haemoglobin A1c is associated with carotid intima-media thickness in a Chinese population. Clin Endocrinol (Oxf) 2011; 75:780-5. doi: 10.1111/j.1365-2265.2011.04129.x.

11. Saba L, Ikeda N, Deidda M, Araki T, Molinari F, Meiburger KM, et al. Association of automated carotid IMT measurement and $\mathrm{HbA1c}$ in Japanese patients with coronary artery disease. Diabetes Res Clin Pract 2013; 100:348-53. doi: 10.1016/j.diabres.2013.03.032.

12. Shaikh NA, Bhatty S, Irfan M, Khatri G, Vaswani AS, Jakhrani N. requency, characteristics and risk factors of carotid artery stenosis in ischaemic stroke patients at Civil Hospital Karachi. J Pak Med Assoc 2010; 60:8-12.

13. Gill BU, Saleemi S, Abbas T, Qureshi BA, Bukhari NI. Frequency of severe carotid artery stenosis in diabetic patients having triple vessel coronary artery disease. Pak Heart J 2013; 46:133-8.

14. Choi SW, Shin MH, Yun WJ, Kim HY, Lee YH, Kweon SS, et al. Association between hemoglobin A1c, carotid atherosclerosis, arterial stiffness, and peripheral arterial disease in Korean type 2 diabetic patients. J Diabetes Complications 2011; 25:7-13. doi: 10.1016/j.jdiacomp.2009.12.001.

15. Alkhunizan, M, Alkhenizan A, Basudan L. Prevalence of mild cognitive impairment and dementia in Saudi Arabia: A community-based study. Dement Geriatr Cogn Dis Extra 2018; 8:98-103. doi: $10.1159 / 000487231$.

16. Zafar A, Al-Khamis FA, Al-Bakr AI, Alsulaiman AA, Msmar AH. Risk factors and subtypes of acute ischemic stroke. A study at King Fahd Hospital of the University. Neurosciences (Riyadh) 2016; 21:246-51. doi: 10.17712/nsj.2016.3.20150731.

17. Aho K, Harmsen P, Hatano S, Marquardsen J, Smirnov VE, Strasser T. Cerebrovascular disease in the community: Results of a WHO collaborative study. Bull World Health Organ 1980; 58:113-30.

18. Touboul PJ, Hennerici MG, Meairs S, Adams H, Amarenco P, Bornstein N, et al. Mannheim carotid intima-media thickness and plaque consensus (2004-2006-2011): An update on behalf of the Advisory Board of the 3rd, 4th and 5th Watching the Risk Symposia, at the 13th, 15th and 20th European Stroke Conferences, Mannheim, Germany, 2004, Brussels, Belgium, 2006, and Hamburg, Germany, 2011. Cerebrovasc Dis 2012; 34:290-6. doi: $10.1159 / 000343145$.

19. Hansa G, Bhargava K, Bansal M, Tandon S, Kasliwal RR. Carotid intima-media thickness and coronary artery disease: An Indian perspective. Asian Cardiovasc Thorac Ann 2003; 11:217-21. doi: 10.11 77/021849230301100308.

20. Singh AS, Atam V, Chaudhary SC, Sawlani KK, Patel ML, Saraf S, et al. Relation of glycated hemoglobin with carotid atherosclerosis in ischemic stroke patients: An observational study in Indian population. Ann Indian Acad Neurol 2013; 16:185-9. doi: 10.4103/0972-2327.112462.

21. Stein JH, Korcarz CE, Hurst RT, Lonn E, Kendall CB, Mohler ER, et al. Use of carotid ultrasound to identify subclinical vascular disease and evaluate cardiovascular disease risk: A consensus statement from the American Society of Echocardiography Carotid Intima-Media Thickness Task Force - Endorsed by the Society for Vascular Medicine. J Am Soc Echocardiogr 2008; 21:93-111. doi: 10.1016/j.echo.2007.11.011.
22. National Glycohemoglobin Standardization Program. List of NGSP certified methods. From: www.ngsp.org/docs/methods. pdf Accessed: Mar 2018

23. American Diabetes Association. Classification and diagnosis of diabetes. Diabetes Care 2016; 39:S13-22. doi: 10.2337/dc16-S005.

24. Expert Panel on Detection, Evaluation, and Treatment of High Blood Cholesterol in Adults. Executive summary of the Third Report of the National Cholesterol Education Program (NCEP) Expert Panel on Detection, Evaluation and Treatment of High Blood Cholesterol in Adults (Adult Treatment Panel III). JAMA 2001; 285:2486-97. doi: 10.1001/jama.285.19.2486.

25. Eapen DJ, Kalra GL, Rifai L, Eapen CA, Merchant N, Khan BV. Raising HDL cholesterol in women. Int J Womens Health 2010; 1:181-91. doi: 10.2147/IJWH.S5110.

26. Di Pino A, Scicali R, Calanna S, Urbano F, Mantegna C, Rabuazzo AM, et al. Cardiovascular risk profile in subjects with prediabetes and new-onset type 2 diabetes identified by HbA (1c) according to American Diabetes Association criteria. Diab etes Care 2014; 37:1447-53. doi: 10.2337/dc13-2357.

27. Fang FS, Li ZB, Li CL, Tian H, Li J, Cheng XL. Influence of glycemic variability on the HbA1c level in elderly male patients with type 2 diabetes. Intern Med 2012; 51:3109-13. doi: 10.2169/ internalmedicine.51.8077.

28. Ceriello A, Esposito K, Piconi L, Ihnat MA, Thorpe JE, Testa R, et al. Oscillating glucose is more deleterious to endothelial function and oxidative stress than mean glucose in normal and type 2 diabetic patients. Diabetes 2008; 57:1349-54. doi: 10.23 37/db08-0063.

29. Mostaza JM, Lahoz C, Salinero-Fort MA, de Burgos-Lunar C, Laguna F, Estirado E, et al. Carotid atherosclerosis severity in relation to glycemic status: A cross-sectional population study. Atherosclerosis 2015; 242:377-82. doi: 10.1016/j.atherosclero sis.2015.07.028.

30. Noh M, Kwon H, Jung CH, Kwon SU, Kim MS, Lee WJ, et al. Impact of diabetes duration and degree of carotid artery stenosis on major adverse cardiovascular events: A single center, retrospective, observational cohort study. Cardiovasc Diabetol 2017; 16:74. doi: 10.1186/s12933-017-0556-0.

31. Meschia JF, Bushnell C, Boden-Albala B, Braun LT, Bravata DM, Chaturvedi $\mathrm{S}$, et al. Guidelines for the primary prevention of stroke: A statement for healthcare professionals from the American Heart Association/American Stroke Association. Stroke 2014; 45:3754-832. doi: 10.1161/STR.0000000000000046.

32. O'Leary DH, Polak JF, Kronmal RA, Manolio TA, Burke GL, Wolfson SK Jr. Carotid-artery intima and media thickness as a risk factor for myocardial infarction and stroke in older adults: Cardiovascular Health Study Collaborative Research Group. N Engl J Med 1999; 340:14-22. doi: 10.1056/NEJM1999010734 00103.

33. Deleu D, Inshasi J, Akhtar N, Ali J, Vurgese T, Ali S, et al. Risk factors, management and outcome of subtypes of ischemic stroke: A stroke registry from the Arabian Gulf. J Neurol Sci 2011; 300:142-7. doi: 10.1016/j.jns.2010.08.023.

34. Saha A, Sinha PK, Paul R, Bandyopadhyay R, Biswas K, Banerjee AK. Study of carotid intima media thickness and its correlation with novel risk factors in ischemic stroke. Neurol Asia 2011; 16:25-31.

35. Lee EJ, Kim HJ, Bae JM, Kim JC, Han HJ, Park CS, et al. Relevance of common carotid intima-media thickness and carotid plaque as risk factors for ischemic stroke in patients with type 2 diabetes mellitus. AJNR Am J Neuroradiol 2007; 28:916-19.

36. Cardoso CR, Marques CE, Leite NC, Salles GF. Factors associated with carotid intima-media thickness and carotid plaques in type 2 diabetic patients. J Hypertens 2012; 30:940-7. doi: 10.10 97/HJH.0b013e328352aba6.

37. Kowall B, Ebert N, Then C, Thiery J, Koenig W, Meisinger C, et al. Associations between blood glucose and carotid intimamedia thickness disappear after adjustment for shared risk factors: The KORA F4 study. PLoS One 2012; 7:e52590. doi: 10.13 71/journal.pone.0052590 
38. Buratti L, Cagnetti C, Balucani C, Viticchi G, Falsetti L, Luzzi S, et al. Blood pressure variability and stroke outcome in patients with internal carotid artery occlusion. J Neurol Sci 2014; 339:164-8. doi: 10.1016/j.jns.2014.02.007.
39. Manning LS, Rothwell PM, Potter JF, Robinson TG. Prognostic significance of short-term blood pressure variability in acute stroke: Systematic review. Stroke 2015; 46:2482-90. doi: 10.1161/ STROKEAHA.115.010075 